\title{
IS THERE PROPER PRESENTATION OF FINANCIAL DATA IN SUPPLY CHAIN ANALYSIS TO SUPPORT EFFECTIVE MANAGEMENT DECISION MAKING?
}

\author{
Mysore Ramaswamy, Southern University, Baton Rouge, LA, mysore@acm.org \\ Richard Calvasina, University of West Florida, Pensacola, FL, rcalvasi@uwf.edu \\ Eugene Calvasina, Southern University, Baton Rouge,LA, ejcalvasina@cox.net \\ Gerald Calvasina, Southern Utah University, Cedar City, UT, calvasina@suu.edu
}

\begin{abstract}
Supply chain analysis involves using a portion of value chain information. In fact, supply chain can be defined as part of the value chain associated with producing and delivering a product or service to a customer. Successful supply chain management depends on the strategic decisions taken at various stages of the supply chain, and especially at that part of the chain that affects the actual production. Therefore the availability of information required to make optimal decisions becomes critical. While the situation has vastly improved in many areas, data capturing is still problematic in some areas. In this paper, the principle area being studied is the evaluation of customers as to whether or not they are profitable and should be kept or eliminated and the information distortion that occurs while this critical information is being captured. A method to eliminate this problem is also presented..
\end{abstract}

Keywords: Accounting Information Systems, Decision Support Systems, Information Distortion, Real Time Economy

\section{INTRODUCTION}

Organizations are constantly expanding the scope of cost-reduction initiatives to include both upstream (supplier) and downstream (customer) members of their supply chains [12]. The current business environment requires managers to be much more efficient when managing their cash flows. They must be much quicker and knowledgeable decision makers as they manage their cash flows, receivables and payables, on a day-to-day basis[26]. The real time enterprise can be compared to a giant spreadsheet in which new information, such as an order, is automatically processed and percolates through a firm's computer systems and those of its suppliers. The current situation is aptly described by the following statement of former Securities and Exchange Commission (SEC) Commissioner Cynthia Glassman: "The current questions about the ability of our accounting and reporting framework to communicate meaningful information to investors arise, in part, because the economy continues to evolve at a rapid pace, while reporting standards and mechanisms are in a catch-up mode. Globalization and the emergence of new economies and capital markets have increased dramatically. Advances in technology, including the emergence of the Internet, faster and more ubiquitous and other technological developments, have changed the way companies do business, as well as changing the types of financial arrangements and instruments that businesses utilize. As the business world has become more complex, so have financial reports and accounting standards [25]."

In a typical manufacturing enterprise, the supply chain model "refers to the flow of products and services from suppliers through to the consumers [27]." Typically the supply chain consists of the following sequence of activities: purchasing, production, marketing and sales, distribution, and customer service. The objective is to offer the customer a level of value that exceeds the cost of activities [14, 16, and 27]. In addition to the above primary value chain activities, we also need to consider the following supporting activities: firm infrastructure, human resource management, technology development, and procurement. Supply chain management (SCM) can be defined as the combination of art and science of improving the way an enterprise finds the raw components it needs to make a product and delivers it to customers. Viewed from this perspective, SCM is an important part of the overall value chain model. This approach is useful in analyzing the impact of Information and Communications Technologies (ICT) on the manufacturing environment [3].

The Financial Supply Chain is also being increasingly recognized as an area offering significant potential for generating bottom-line improvements and creating competitive advantage. According to Killen Associates, a typical 


\section{Issues in Information Systems \\ Volume 16, Issue I, pp. 102-111, 2015}

billion-dollar company spends approximately $\$ 27$ million annually for unnecessary working capital and inefficient processing functions because they lack visibility into the Financial Supply Chain and receivables [3, 9]. It has also been estimated that the total value locked up in inefficiencies associated with the global supply chain are between 500 billion and one trillion US dollars.

Enterprise Resource Planning (ERP) systems have been developed with the twin objectives of reducing operational costs and help make better quality managerial decision making by producing reports that can be used throughout the enterprise [5, 8]. 'Work order' is the basic transaction upon which ERP implementations such as SAP have been built. As the production process progresses, the same system will link the consumption of inventory as well as track the production, shipping and accounts receivable [4]. The challenge to the management is to use the available information at the operational level for making decisions at the tactical and strategic levels. ERP systems provide vast amounts of information by utilizing their highly efficient transactional engines. The vast amounts of data creates an undesirable consequence. This increased amount of data results in an increase in the complexity in the decision-making process at the higher levels of management due to this increased volume of information available to managers. This problem is further compounded because the information has been generated from a 'template' approach and does not differentiate between the different types of data. Clearly, there is a need for an interface between transactional data / information and tactical decision-making. Problems with operational data can occur due to missing data, invalid data, or inaccurate data. Conceptual data errors occur as a result of imprecise or ambiguous definition of data. Errors in organizational data occur due to disconnects between organizations that generate and/or use data.

This paper is organized as follows. Features of accounting information are described in the next section. This is followed by a discussion on the type of distortion that occurs in presenting financial data. Automation of financial information processing is discussed subsequently. A summary is presented in the last section.

\section{FEATURES OF ACCOUNTING INFORMATION}

The output of an accounting information system has to meet the user's requirements. There are some features that ensure quality. For example, IFRS - International Financial Reporting Standards, requires that accounting information is understandable, relevant, reliable, and comparable and also has quantitative and qualitative characteristics. In addition, accounting information can be used by business owners to conduct a financial analysis of their companies [1]. Quantitative characteristics refer to the calculation of financial transactions. Qualitative characteristics include the business owner's perceived importance of financial information. Incorrect or inappropriate information can adversely affect managerial decision-making.

Accounting information must be understandable. This is an important qualitative characteristic for small business owners as many of them do not have strong accounting background. Financial information that is too technical or cannot be understood by a layperson can be ineffective for business owners. Business owners need accounting information that is applicable to the business decision at hand [21,23]. Accounting information has to relate to a specific time period and contain information regarding individual business functions that will enable business owners to conduct a trend analysis when reviewing financial information.

The need for reforming financial reporting using the capabilities of information technology was first initiated by the Enhanced Business Reporting Consortium (EBRC) [25]. This is a consortium of stakeholders collaborating to improve the quality, integrity, and transparency of information used for decision-making in a cost effective, time efficient manner. Figure 1 illustrates the components of EBRC Model. The major components are: System Reliability, Financial Measures, Non-Financial Measures, Information Discrimination, Understandable Disclosures, and Corporate Accountability $[11,13]$. The problems of business reporting are succinctly described in the following statement by Rebecca McEnally, project director of the Comprehensive Business Reporting Model: "As businesses develop new products and services, the financial reporting model must keep pace ensuring that financial statements are relevant, clear, accurate, and complete. Investors worldwide are too often in the dark about the true value of companies because accounting practices fail to reflect the economics of today's business operations [25]." 
The problems in business reporting are compounded by the changes that are occurring in the way in which firms transform capital into returns. In the past, the main function of the firm was to apply unskilled labor into physical assets, which essentially meant that the reporting concentrated on the disposition of those tangible assets, adequately captured firm performance. Nowadays firms create value by the use of such intangible assets as knowledge and the skills of its workers with the result that the relationship between its physical assets and its performance is greatly reduced [25]. This will result in two types of problems: (a) A measurement issue of how to account for the presence and role of intangibles, and (b) An incentive problem in that this weaker relationship opens up a wider scope for managers to manipulate earnings.

Vasarhelyi and Alles [25] provide the following example. Cisco Systems wrote-down its inventory by $\$ 2.25$ billion, an amount larger than the inventory value in its books. One explanation is that the write-down related to the value of inventories that could not be sold by its suppliers in the supply chain where Cisco had a contractual or moral obligation. In particular, during the e-commerce boom, Cisco had offered many of its dot-com customers' vendor financing in exchange for sales contracts, while signing contracts itself with downstream suppliers in anticipation of tight demand. These obligations were not reflected anywhere in the financial statements, thus, in hindsight, clearly overstating the firm's profit potential. Of course, even granting these measurement problems, there was also the suspicion that the sheer magnitude of the write-off resulted from the use of the well-known tactic of the 'big bath', in which if reporting some bad news is unavoidable, the best option is to take advantage by writing off all other possible bad news in advance in one shot, thereby creating reserves to boost income in the future.

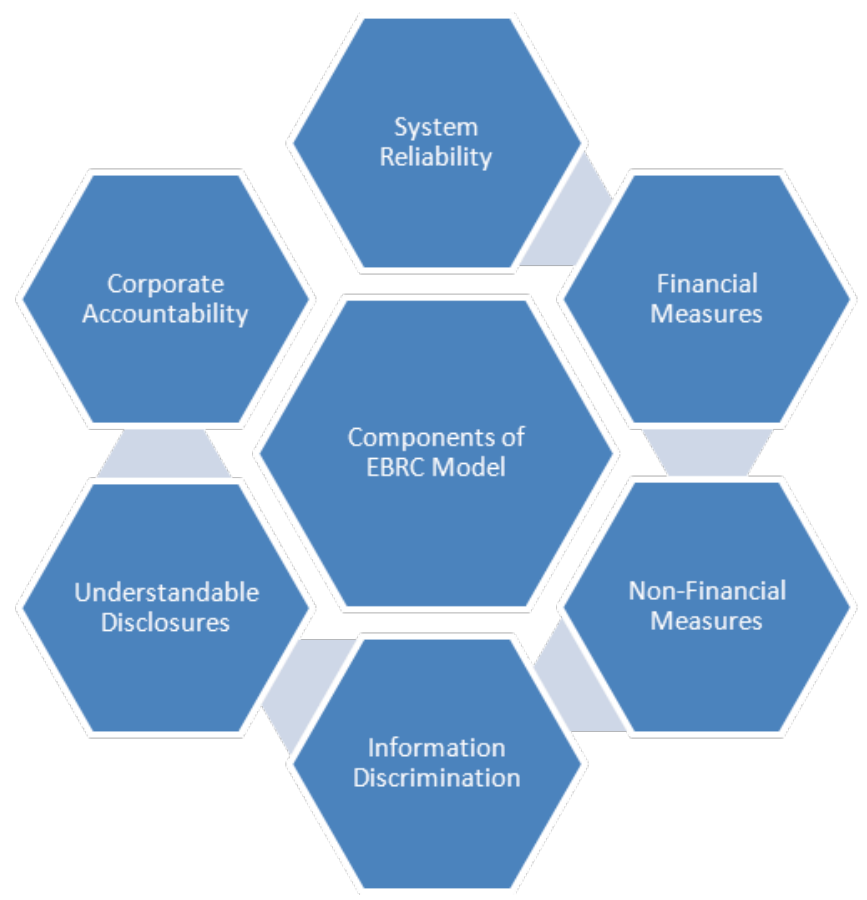

Figure 1. Components of Enhanced Business Reporting Consortium (EBRC) Model (Adapted from [25])

The above example illustrates the difficulty that users face today with financial reports. This is not an example of fraud, but rather an example of the systemic inability of the current financial reporting system to meet the needs of users to understand the ways in which complex organizations perform and to hold their managers accountable. This example also indicates how even long established and relatively uncontroversial rules on inventory evaluation could not guarantee that different firms will apply those rules in the same way, given the underlying ambiguity of what is being measured. Evidently, a strong case can be made for more information disclosure to enable stakeholders to better discern the purpose and meaning of each transaction. 


\section{Issues in Information Systems \\ Volume 16, Issue I, pp. 102-111, 2015}

\section{DISTORTION OF FINANCIAL DATA}

In this Section, the importance of capturing accurate financial data that will be fed to automated systems such as financial modules of Enterprise Resource Planning (ERP) systems is illustrated by an example which typically occurs in any manufacturing scenario. Appendices I - IV refer to the financial data used in this example. The Value Chain consists of the set of activities that transforms raw resources into the goods and services end users (households, for example) purchase and consume [14]. The functional areas contained in the Value Chain consist of: Research and Development, Design, Purchasing, Production, Marketing and Sales, Distribution and Customer Service [14]. The process, involving the assignment of costs to a particular product, starts with the identification of the costs associated with each activity or functional area in the supply chain. The second step involves the identification of the appropriate Cost Driver to assign the costs to the product. Once the appropriate Cost Driver has been identified, it becomes a simple step to assign a portion of the costs of each individual activity to each product based on their determined use of the Cost Driver. An example of a Supply Chain analysis for a fictitious product is shown in APPENDIX I. The results of the Supply Chain analysis using the full cost concept required by the Financial Accounting Standards Board (FASB) results in reporting a net loss of $\$ 50,000$ for Product A. This results from apportioning a share of fixed costs to the product. The question that needs to be resolved is the nature of the fixed costs. If product $\mathrm{A}$ is eliminated, will the fixed costs disappear or will they need to be absorbed by another product or products.

In order to properly analyze the costs in a Supply Chain, they must be categorized properly into three distinct groups: variable costs, discretionary fixed costs or committed fixed costs. Just grouping the costs by activity within the Supply Chain, and then assigning them to products using cost drivers will result in presenting an erroneous picture. When determining whether or not to keep or drop a product, it is imperative that the type of cost be identified. If a product is dropped, will the cost go away or remain. Variable costs can be eliminated and discretionary fixed costs may be eliminated without a negative impact to the company's income statement. Committed fixed cost usually must be absorbed by another product or products and usually result in a loss entry in the income statement

If the decision is made to drop Product A based on the Supply Chain analysis in Appendix I, the decision maker following the full cost FASB requirement would naturally assume that all the costs identified with the activities to bring Product A from the design stage to the market stage would all go away without penalty. But will they? If Product A goes away, chances are that the Research and Development activity/department, the Design activity/department, the Purchasing activity/department, and the Customer Service activity/department will have little or no change in their total operating costs. The Marketing and Sales activity/department may have cost reductions involving commissions and advertising expenses. The Distribution activity/department may have significant cost reductions if the preponderance of their costs is actually freight out costs. And finally, the Production activity/department incurs Direct Material, Direct Labor and Factory Overhead costs. Direct Material and Direct labor are assumed to be true variable costs or in Direct Labor's case it may be a discretionary fixed cost. Factory overhead is another story. Factory overhead is a capacity cost that provides the capability for operating within a specific range of activity. With the dropping of one product, there will likely be little or no change in the total cost incurred for Factory Overhead.

In Appendix II, the information in Appendix I has been rearranged using a segment margin approach. In this approach, variable costs and fixed costs identified with a given product will be shown on the statement. Common costs that must be allocated between products are not shown on the statement. The fixed costs identified with the product are further separated into discretionary and committed fixed costs. In most cases the fixed costs involved are common fixed costs that have to be allocated to the product. In such cases, allocated fixed costs are never shown since these are committed fixed costs and must be absorbed by other products. In addition, the assumption has been made that the fixed costs associated with various activities shown on the value chain are common fixed costs that will not change if Product $\mathrm{A}$ is discontinued. If some of the fixed costs had been determined to be directly associated with Product A, they would have been shown and used to calculate the segment margin for Product A. However, further analysis would have been required to determine if the fixed costs directly identified with Product A were discretionary or committed fixed costs in order to provide sufficient information upon which to base a product elimination decision. 


\section{Issues in Information Systems \\ Volume 16, Issue I, pp. 102-111, 2015}

The rather naive analysis shown in Appendix I based on the full cost requirement might lead someone to the conclusion that if they eliminate Product A profits for the company would automatically increase by $\$ 50,000$. Proper analysis using the contribution margin approach would show the manager that if Product A is eliminated, overall company profits will be negatively impacted by $\$ 450,000$. When the variable costs and discretionary fixed costs directly associated with product $\mathrm{A}$ are eliminated, product $\mathrm{A}$ has a positive contribution towards common fixed costs and profitability of $\$ 450,000$. The common fixed costs that have been allocated to Product A using cost drivers are not going to be eliminated with Product A. They will continue and will have to be absorbed by other products being produced by the company.

The Supply Chain analysis involves using a portion of the Value Chain information. As a result, the problems caused by the use of the full cost concept required by FASB in the Value Chain analysis are also present in Supply Chain analysis. The Supply Chain is that part of the Value Chain associated with producing and delivering a product or service to a customer. As such, the associated activities would be Production, Marketing and Sales, Distribution and Customer Service costs. The focus in Supply Chain analysis is on the individual customer being served, as opposed to individual products, and involves a determination of whether or not having a customer results in a profit or loss for the company.

In Appendix III, an evaluation of Customer Q is presented. While Revenues and Distribution can be readily identified with Customer Q, Cost of Goods Sold, costs for Customer Service, and costs for Marketing and Sales are a different story. These costs are assigned to Customer Q in part or wholly through the use of Cost Drivers. In the presentation below, Customer $\mathrm{Q}$ is shown to be an unprofitable customer. Costs assigned to this customer exceed revenue by $\$ 3,000$. If the decision rule is to reject unprofitable customers, this customer would be told to find another supplier. The methodology used to support the decision rule being used to evaluate Customer Q, however, is inappropriate. Instead of evaluating this person using the full cost methodology to determine profitability, Customer Q should be evaluated on the basis of their contribution toward common costs and profitability.

In other words, a segment margin analysis should be used. In Appendix IV, Customer Q is evaluated by determining what revenues and costs are directly attributed to Customer Q. If a cost is a common fixed cost, it has to be assigned using some Allocation Methodology and will normally not change in total if Customer Q is dropped. Therefore, it is not used in the analysis. In Appendix IV, it has been assumed that none of the Customer Service costs will be eliminated with the dropping of Customer Q and that only a portion of the Cost of Goods Sold and the Marketing and Sales costs will be eliminated if Customer Q is dropped. The Distribution costs will be eliminated with no shipments of merchandise to Customer Q. The result is a segment margin that is positive. The costs that have not been used in the analysis will continue whether or not we keep customer Q. If we drop Customer Q, the result will be a $\$ 21,000$ drop in company profits instead of the hoped for increase in profitability of $\$ 3,000$ based on the Supply chain Analysis in Appendix III.

The allocation of common costs, which is a requirement of financial accounting reporting is in direct opposition to the needs of the manager in the evaluation of products and customers. There are two problems involved with allocated common costs. The first relies on the fact that the evaluation using allocated common costs can be changed simply by changing how the costs are allocated. There is an allocation bias involved in any evaluation using allocated costs. Segment Margin analysis requires that only costs that can be directly associated with a product or segment may be used in the analysis. The second problem involves the type of fixed cost. Are they discretionary or committed? Most common costs are fixed in nature. By using an allocation base/cost driver, the appearance that the cost is variable in nature is given. Nothing could be further from the truth. While we make short-term decisions that have long term ramifications, when a product or customer is removed because they are unprofitable, the committed fixed costs continue and they are simply allocated to the remaining products and/or customers. The result is a lowering of the company profits rather than an increase. With Segment Margin analysis, the error in eliminating positive contributing customers is eliminated. If a segment has a positive Segment Margin, that is defined as revenues minus directly associated costs, positive contributing products and/or customers will not be eliminated. 


\section{Issues in Information Systems \\ Volume 16, Issue I, pp. 102-111, 2015}

\section{FINANCIAL PROCESS AUTOMATION}

With the advent of the computer and the UPC labeling much has been done to improve the supply of information necessary to improve the management of the financial supply chain. However, no matter how good the data flow is to provide management with information, it still starts with a sound plan. With a sound plan and good current information, management can do a much more efficient job of controlling inventory levels and preserving cash. Despite the new technological innovations for processing information, proper control over cash payments is still necessary. In other words, the need for the proper documentation that was contained in the Voucher Package is still necessary. In the modern age, the documentation contained in the package is somewhat different. No longer are there Purchase Requisitions and individual Purchase Orders. If the company is operating with a Just-In-Time system, there are also no Receiving Reports. The Vendor Invoice is electronically sent. In the current system, the purchasing department evaluates vendors to determine if they can provide the necessary items in the quantity and quality desired. If the vendor passes, a long term purchase contract is arranged. The vendor is given a copy of the production schedule that details what is needed and when it is needed. The vendor is then required to deliver what is needed, when it is needed. When a Vendor Invoice is transmitted electronically by the vendor to the customer, it is evaluated to determine if it is coming from an authorized vendor, for contracted items, in the quantity called for by the production schedule $[12,18]$. If everything agrees, payment is authorized and scheduled for payment on the due date. On the proper due date, payment is transmitted electronically. This results in a great deal of time being saved in the processing of vendor invoices for payment. While accounts receivable is now electronically processed, the key to reducing float has come about through the electronic processing of payments. No longer is there a lengthy wait for a company to receive its money because the customer dropped the payment in the mail. With electronic payment the firm receives its money promptly and has it in the bank that day. Thus, the money is available in a much more expeditious time.

Bloated inventories because we ordered the wrong items, or we produced the wrong products, or we overproduced should be a thing of the past. With a sound plan and the information now provided by the computerized systems, management can eliminate overstocking and obsolete inventories. This still requires a constant monitoring of actual sales and a reconciliation of current inventory levels and production plans to determine if the change in the actual sales pattern has changed significantly from the sales budget and as a result requires a change in production plans.

While just a few years ago, less than one percent of U.S. companies were transacting electronically, that number is over 20 percent [15]. This increase is mainly due to the new technologies that can convert any type of file - paper, flat, or Electronic Data Interchange - into digital format. Three types of approaches are available for e-invoicing. In the seller-focused method, companies adjust their processes to accommodate their suppliers' invoicing capabilities. In the buyer-focused approach, vendors adapt to the seller's accounting process. In the consolidated approach, a third party accepts vendor invoices in whatever format works best for them, and provides both the customer and the vendors with an electronic portal to manage all accounts payable and accounts receivable transactions.

Innovations in Radiofrequency Identification (RFID) have a gone a long way in answering the information processing challenges that can occur in financial supply chains. Nowadays, large enterprises like Wal-Mart require their vendors to place RFID tags on incoming pallets. The adoption of RFID is a strategic decision. For unfettered, un-mandated, adoption to take place an organization must be able to justify the cost of the investments in the technology in terms of when and how they could expect to reap the benefits of that investment. In most cases, these benefits have a direct impact on the bottom line, the savings. It is therefore a primary driver for such voluntary and no-strings-attached adoption [8]. Organization information systems have evolved significantly in the last fifty years, and they will continue to evolve. They have changed from paper and pencil to computer driven systems. While the means have changed significantly, the providers have also changed and in our estimation will continue to change. At one time the management accountant was the principal provider of information for strategic decision-making. Today, the managerial accountant has withdrawn from this function, and is now a recipient of information provided by the organization information system. The MIS system is now the provider of basic information such as inventories, personnel costs, equipment costs, etc. In short the ERP system collects data and distributes it to the relevant users. 


\section{Issues in Information Systems \\ Volume 16, Issue I, pp. 102-111, 2015}

It is assumed that the financial accounting system is independent of an organizations MIS system. While this may be true in part, it relies heavily on this system to prepare its reports. These reports in many respects are oriented to outsiders who will use these reports to assess the financial condition of the firm. While important, they are not in a framework for making executive decisions. This shortcoming can be overcome by the MIS system creating the necessary reports.

\section{CONCLUSION}

Contemporary information systems provide the real time data used by accountants to prepare financial documents. Jim Shepherd of AMR Research states that the notion that a company can transform itself into an e-business by simply using a piece of software and adding it to its existing infrastructure is wrong and dangerous [18]. As supply chain management becomes more integrated with financial supply chain, it is critical that we have reliable information sources. In order to fully realize the positive impact of IT, it is necessary to integrate physical, informational and financial supply chains. In this paper, we have analyzed various transactions that take place in a typical financial supply chain at the enterprise level. Future research involves developing a framework that enables extraction of relevant information that is needed for optimal results. We also plan to study the ways in which the new innovations in information technology can be harnessed in the context of inventory management and its effect on the overall financial supply chain efficiency.

\section{REFERENCES}

1. Alves, M. C. G. (2010). Information technology roles in accounting tasks: A multiple-case study. International Journal of Trade, Economics, and Finance, 1(1), 103-107.

2. Atkinson, A. A., Kaplan, R. S., Matsumura, E. M., \& Young, S. M. (2001), Management accounting, Upper Saddle River, NJ: Prentice Hall.

3. Barry, J. (2003). Lessons learned from physical supply chain, Inside Supply Management, 14(5), 21.

4. Carbo, B. (2002). Align the organization for improved supply chain performance, ASCET, 4, May 15.

5. Carlton, F., \& Adam, F. (2005). Understanding the impact of enterprise systems on management decision making: An agenda for future research. The Electronic Journal of Information Systems Evaluation, 8(2), 99106.

6. Fontelera, J. (2007). Quest for the RFID supply-chain holy grail: ROI, Converting Magazine, 25(9), 35-35.

7. Garrison, R. H., Noreen, E., Brewer, P. (2003). Managerial accounting. New York, NY: McGraw Hill / Irwin.

8. Ge, M., \& Helfert, M. (2007). A review of information quality research in information system and decision making. Proceedings of the IADIS International Conference on e-Society, 467-470.

9. Handfield, R., \& Nichols, E. (2002). Supply chain redesign. Upper Saddle River, NJ: Prentice Hall.

10. Hardgrave, B. C., Langford, S., Waller, M., \& Miller, R. (2008). Measuring the impact of RFID on out of dtocks at Wal-Mart, MIS Quarterly Executive, 7(4).

11. Hartley-Urquhart, R. (2006). Managing the financial supply chain. Supply Chain Management Review.

12. Healy, P. M., \& Palepu, K. G. (2001). Information asymmetry, corporate disclosure, and the capital markets: A review of the empirical disclosure literature. Journal of Accounting and Economics, 31, 405-440.

13. Hirschey, M. (2000). Managerial economics. New York, N.Y.: The Dryden Press.

14. Hongren, C. T., Datar, S. M., \& Rajan, M. V. (2015). Cost accounting: A managerial emphasis. $15^{\text {th }}$ edition. Upper Saddle River, N.J.: Prentice Hall.

15. Landeen, D. (2010). Automating the financial supply chain: A strategy for growth, Supply Chain Brain, Available: $\mathrm{http}: / / \mathrm{www}$. supplychainbrain.com/content/index.php?id=7098\&type=98\&tx_ ttnews\%5Btt_news\%5D=7159\&cHash=da03e20e36

16. Lanen, William N., Anderson, S. W., \& Maher, M. W. (2014) Fundamentals of cost accounting (4 ${ }^{\text {th }}$ Edition), New York, New York: McGraw Hill and Co.

17. Lee, J. Y. (1987). Managerial accounting changes for the 1990s. Artesia, CA: McKay Business Systems.

18. Memis, M. U. (2011). E-accounting: An evaluation on the Turkish case. European Journal of Economics, Finance, and Administrative Sciences, (38), 155-163.

19. Nancy W. (2000), Fundamental management accounting concepts. Boston, MA: McGraw Hill. 


\section{Issues in Information Systems}

Volume 16, Issue I, pp. 102-111, 2015

20. Neuman, B. R., \& Jaouen, P. R. (1986). Kanban, ZIPS, and Cost Accounting: A Case Study. In Focus on Industry, Journal of Accountancy, 132-141.

21. Ogden, J. A., Petersen, K. J., Carter, J. R., \& Monczka, R. M. (2005). Supply management strategies for the future: A delphi study. The Journal of Supply Chain Management, 41(3), 29-48.

22. Sacer, Ivana M., Zager K., \& Tusek B. (2006). Accounting information system's quality as the ground for quality business reporting. Proceedings of IADIS International Conference on e-Commerce, 59-64.

23. Sori, Z. M. (2009). Accounting information systems (AIS) and knowledge management: A case study. American Journal of Scientific Research, (4), 36 - 44.

24. Vakilifard, H., Nikoomaram, H., Rostami, V., \& Salehi, M. (2011). Information asymmetry gap analysis between users and preparers of accounting information under qualitative characteristic of financial reporting: Evidences of Iran. International Journal of Academic Research, 3(2), 231-241.

25. Vasarhelyi, M. A., \& Alles, M. G. (2008). The "now" and the traditional accounting reporting model: Opportunities and challenges for AIS research. International Journal of Accounting Information Systems, (9), 227-239.

26. Vasarhelyi, M. \& Alles, M. G. (2008). Reengineering business reporting creating a test bed for technology driven reporting. International Journal of Digital Accounting Research, 8(14), 97-114.

27. Whitecotton, S. Libby, R., \& Phillips, F., (2013), Managerial, $2^{\text {nd }}$ Edition. New York, NY: McGraw-Hill Irwin, 164-169 


\section{Issues in Information Systems}

Volume 16, Issue I, pp. 102-111, 2015

\section{Appendix I}

Product A

Value Chain Analysis
Revenue

Costs:

Research and Development

Design

Purchasing

Production

Marketing and Sales

Distribution

Customer Service

Net Loss
$\$ 1,000,000$

100,000

50,000

75,000

600,000

75,000

100,000

50,000

$(\$ 50,000)$

\section{Appendix II}

Product A

Contribution Margin Analysis

Revenue

Variable Costs:

Production

Marketing and Sales

Distribution

Segment Margin
$\$ 1,000,000$

400,000

50,000

100,000

$\$ 450,000$

\section{Appendix III \\ Customer Q \\ Supply Chain Analysis}

Revenue

Costs:

Cost of Goods sold

Marketing and Sales

Distribution

Customer Service

Loss

$\$ 60,000$

42,000

6,000

7,000

8,000

$\underline{(\$ 3,000)}$

\section{Appendix IV \\ Customer Q \\ Segment Margin Analysis}

Revenue

$\$ 60,000$

Costs:

Cost of Goods Sold

28,000

Marketing and Sales

4,000

Distribution

7,000

Customer Service 


\section{Issues in Information Systems}

Volume 16, Issue I, pp. 102-111, 2015 